\title{
OPTIMAL DESIGN OF LATERALLY UNRESTRAINED I-BEAMS USING GENETIC ALGORITHM
}

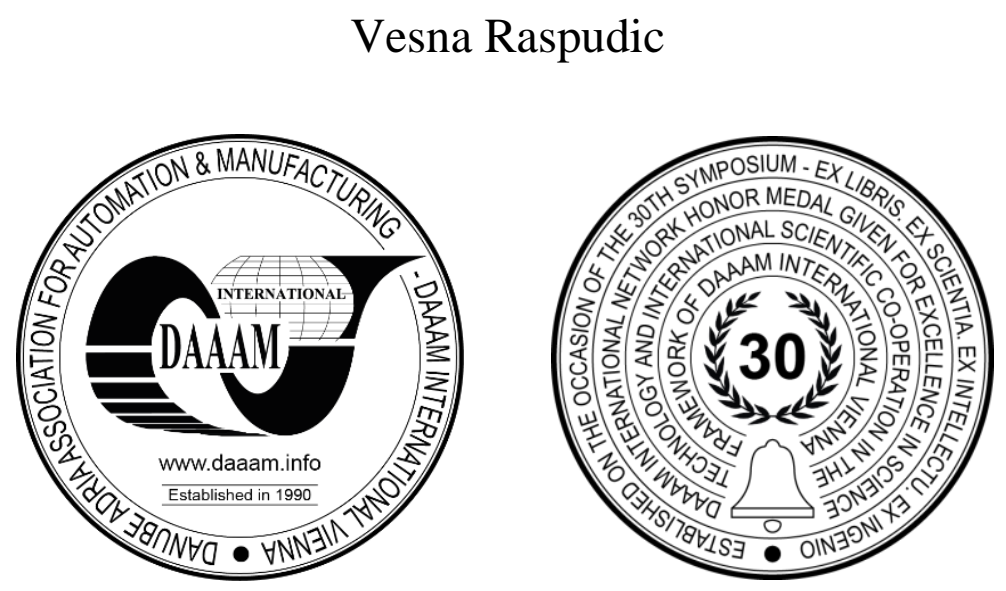

This Publication has to be referred as: Raspudic, V[esna] (2020). Optimal Design of Laterally Unrestrained I-Beams Using Genetic Algorithm, Proceedings of the 31st DAAAM International Symposium, pp.0683-0691, B. Katalinic (Ed.), Published by DAAAM International, ISBN 978-3-902734-29-7, ISSN 1726-9679, Vienna, Austria DOI: $10.2507 / 31$ st.daaam.proceedings.095

\begin{abstract}
Built-up welded I-beams are widely used in modern construction due to their high strength-to-weight ratio and the flexibility of cross-sectional shapes and sizes. However, determining the optimal cross-sectional geometries is a complex problem, as they must meet all the constraints, practical limitations and rules defined in the corresponding design code. The objective of this study is to automatize the procedure for obtaining dimensions of doubly symmetric and monosymmetric I-beams, which minimize the mass of a laterally unrestrained beam subjected to bending around its major axis, satisfying thereby all the practical limitations and constraints according to the European design guidelines. The MATLAB programming platform is used to develop codes for a discrete variable optimization problem by using genetic algorithm. The results indicate to the average percentages of web and flanges area in the total cross-sectional area, as well as that for the considered static system significant weight reduction can be obtained by using monosymmetric I-beams.
\end{abstract}

Keywords: Optimal Design; I-Beam; Lateral torsional buckling; Discrete variable optimization; Genetic Algorithm;

\section{Introduction}

The members of a steel structure used as beams and columns are usually designed with a thin-walled cross-section, and represent a compromise between structural stability and economic efficiency. Typical sections for steel beam-column members are usually I- or H-rolled sections. In some fields of steel structures it is common to use built-up I-sections, which are fabricated by welding together two flanges and a web plate. They can be doubly symmetric with equal flanges or monosymmetric with unequal flanges in order to achieve a more efficient arrangement of material. Built-up I-sections are generally used in situations where rolled steel sections in their standardized sizes are not available to span long distances and carry heavy loads, like long-span floors and roofs in buildings, crane girders and bridges, but also in all other cases where their application is economically justified.

In general, in the limit state design approach given in the Eurocodes, starting cross-section dimensions for built-up profiles are very often chosen by the designer based on his expertise and past experience. Design check is then undertaken to evaluate all the constraints, practical limitations and rules defined in the corresponding design code. This process is often iterative, i.e. if the cross-section does not satisfy them, the dimensions are changed and a new check is performed. 
Thereby, it is essential that the final design should not only satisfy all required design rules, but also represent the most economical solution taking into account the amount of material used and/or the total cost of the construction. As there are usually a large number of design possibilities, selection of the most favourable dimensions can be improved and accelerated by using the optimum design techniques.

The modern optimization techniques use various optimization algorithms. Jarmai et al. investigated the suitability of four conceptually different optimization algorithms for the optimal design of welded doubly symmetric I-beam [1]. The algorithms evaluated include a genetic algorithm, a leap-frog gradient method without line searches, an orthogonal search method requiring no gradients and the differential evolution technique. The works of Gil-Martin and Carbonell-Márquez et al. present the optimization of steel beam-columns based on the Reinforcement Sizing Diagrams (RSD) optimization methodology with Eurocode 3 constraints, which is based on graphical representation of the structural steel area as a function of the web height [2], [3]. Ozbasaran studied the optimal design of prismatic I-section under stress, non-linear deflection and global buckling constraints with the Crow Search Algorithm [4]. This study shows that the conventional use of the smallest predesigned hot-rolled section from the manufacturers' catalogue that satisfies the considered constraints may result in substantial waste of structural material compared to the built-up I-section, which can be manufactured by cutting the plates to the determined dimensions and welding them to each other to form the optimized shape. Lately, there has also been a tendency to combine materials of different strengths in an I-beam design. By changing materials at various locations along the span so that higher strength materials are available at locations of high moment and/or shear, or by using hybrid design with different strength material for flanges than for web, more efficient and economical design can be obtained [5]. Mela \& Heinisuo considered economical use of high strength steels in welded doubly-symmetric I-beams. In addition, hybrid design with flanges and web produced of different steel grades is also treated. The beams are optimized separately for weight and cost, whereby bending and shear resistance are considered and lateral torsional buckling is neglected [6]. There are also works which consider optimal design of built-up tapered Ibeams, like the work of Ozbasaran \& Yilmaz, where the shape optimization of flange and/or web tapered doublysymmetric I-beams is presented and the contribution of flange and/or web tapering and inflection point location to the economical design is discussed [7].

Most of the works dealing with I-section optimization consider doubly symmetric profiles, or in the case of considering monosymmetric cross-sections they use constraints that do not belong to any specific design code, require preliminary sizing of certain dimensions or neglect the influence of lateral torsional buckling. In this paper, the emphasis of optimization is primarily on the influence that lateral torsional buckling has on the behaviour of laterally unsupported beams. When a structural beam/column member, usually slender in nature, has relatively small lateral and torsional stiffness compared to its stiffness in the plane of loading, the member will deflect laterally and twist out of plane when the load reaches a critical limit. This limit is known as the elastic lateral-torsional buckling load, and it is influenced by a number of factors, including cross-sectional shape, the unbraced length and support conditions of the member, the type and position of the applied loads along the member axis, and the location of the applied loads with respect to the centroid axis of the cross section. In an I-beam with a doubly-symmetric cross-section, the compressive and tensile stresses induced by bending balance each other and do not affect the torsional stiffness of the beam. In a beam with a monosymmetric cross-section, the shear centre and the centroid of the cross-section do not coincide. The tensile and compressive stresses do not balance each other and the significance of this can be explained by the Wagner effect, in which the twisting of the member causes the longitudinal bending stresses to exert an additional disturbing torque. When the smaller flange is in compression there is a reduction in the effective torsional rigidity, while the reverse is true when the smaller flange is in tension. Consequently, the resistance to buckling is increased when the larger flange is in compression, and decreased when the smaller flange is in compression [8].

The objective of the study presented in this paper is to automatize the procedure for obtaining optimal dimensions of doubly symmetric and monosymmetric I-beams, which minimize the mass of a laterally unrestrained beam subjected to bending around its major axis, and to point out the possibility of savings in material in case of application of monosymmetric cross sections. Thereby, the practical limitations and constraints according to the Eurocode 3 (EC3) have been included in the optimization constraints. For the analysed static system this implies an appropriate classification of the cross section and consideration of the influence of shear, bending and lateral torsional buckling. The design variables, objective function and constraint conditions used in the optimization technique are described in the following sections. The optimization problem is defined as discrete-variable nonlinear optimization problem and is solved by using genetic algorithm in MATLAB programming platform.

\section{Mixed variable optimization using genetic algorithm}

Optimization can be defined as the process of finding the conditions that give the maximum or minimum value of a function [9]. The optimum seeking methods are also known as mathematical programming techniques and they are useful in finding the minimum of a function of several variables under a prescribed set of inequality and equality constraints. When either the objective or any constraint function is nonlinear in terms of the variables, it is generally referred as constrained nonlinear optimization or a nonlinear programming (NLP) problem. Most non-linear optimization methods assume that design variables are continuous. However, in practical engineering work, it is common that design variables have an integer value or that they have to be selected from a given finite set of values, for example because a design element is only available in a limited set of standard sizes. Such design variables are called discrete variables. 
The mixed continuous-discrete variable optimization problem can be formulated mathematically as follows [10]:

Minimize $f(\mathbf{x})$

subject to:

$$
\begin{aligned}
& g_{j}(\mathbf{x}) \leq 0, \quad \mathrm{j}=1 \text { to } m, \quad h_{k}(\mathbf{x})=0, \quad k=1 \text { to } p \\
& x_{i} \in D_{i}, \quad D_{i}=\left(d_{i 1}, d_{i 2}, \ldots, d_{i q_{i}}\right), \quad i=1 \text { to } n_{d}, \quad x_{i L} \leq x_{i} \leq x_{i U}, \quad i=\left(n_{d}+1\right) \text { to } n
\end{aligned}
$$

where $f$ is the objective function, $g_{j}$ and $h_{k}$ are inequality and equality constraints; $n$ is the number of design variables, whereas the first $n_{d}$ variables are assumed to be discrete, $D_{i}$ is the set of allowable discrete values for the $i$-th discrete variable $x_{i} ; q_{i}$ is the number of allowable discrete values for the $i$-th discrete variable; $x_{i L}$ and $x_{i U}$ are the lower and upper bounds for the continuous design variable $x_{i}$. Many different methods have been proposed for solving mixed integerdiscrete-continuous non-linear programming problems [10]. They can be divided into two basic classes: enumerative and stochastic. The enumerative methods can be with full or partial enumeration, whereas the most common stochastic methods are simulated annealing, genetic algorithms and other nature-inspired search methods.

Genetic algorithm (GA) is a universal stochastic optimization technique, which is capable of finding or at least approaching a global optimum within a bounded domain of permissible solutions to a given problem [11]. GA is a method for solving both constrained and unconstrained optimization problems based on a natural selection process that mimics biological evolution. The process starts with a population (set of designs), randomly generated using the allowable values for each design variable. Each design is assigned a fitness value, usually using the objective function for unconstrained problems or the penalty function for constrained problems. GA uses iterative procedure of generating new population from the previous one using three operators: reproduction, crossover, and mutation. The process is repeated until the convergence criterion is satisfied and the population evolves toward an optimal solution [12]. The programming code of this work was developed in the MATLAB $\AA$ computing environment. The general syntax of function $g a$ in MATLAB is as follows:

$$
\mathbf{x}=\operatorname{ga}(\text { fun, nvars, } A, b,[],[], l b, \text { ub, nonlcon, IntCon, options })
$$

where fun is the function to be minimized, nvars is the number of design variables, $A$ and $b$ define linear inequality constraints, $l b$ and $u b$ are vectors that specify lower and upper bounds of design variables, nonlcon is the function that computes the nonlinear inequality and equality constraints and options define optimisation options. Both of the functions fun and nonlcon have been written as separate .m files, where the constraint functions are formulated based on design constraints and EC3 rules presented in paragraph 3.

GA is well suited for solving mixed integer-discrete-continuous problems, and in most cases it can find the global optimum solution with a high probability. The solution of GA is highly dependent on the right choice of input parameters [13]. In this study, population size is set to 200 , the number of generations to 100 for doubly symmetric, i.e. to 200 for monosymmetric beams, and EliteCount, that specifies how many individuals in the current generation are guaranteed to survive to the next generation, to 20 .

\section{Problem formulation}

The static system for the problem analysed in this study is a simply supported beam with end-fork conditions, i.e. pin supports with free warping (Fig. 1). Permanent $q_{G}$ and variable $q_{Q}$ distributed loads are applied in the vertical plane and cause shear force and bending moment in the beam. A welded doubly symmetric and monosymmetric I-beams are to be designed with minimum weight on the basis of a plastic analysis with Class 1 cross-section.
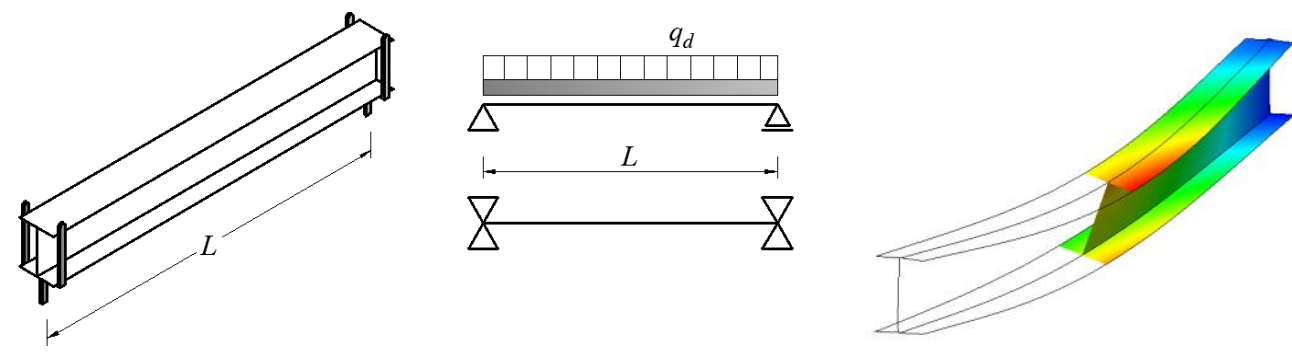

Fig. 1. Static system and lateral torsional bending of a beam

\subsection{Design variables}

The design variables are the dimensions of the cross-section (Fig. 2). The number $n$ of design variables depends on the selected I-beam type. For doubly-symmetric I-beam $n=4$, i.e. the vector of design variables $\mathbf{x}$ includes web height and thickness $\left(h_{w}\right.$ and $\left.t_{w}\right)$ and flanges width and thickness $\left(b_{f}\right.$ and $\left.t_{f}\right)$ : 


$$
\mathbf{x}=\left[h_{w}, t_{w}, b_{f}, t_{f}\right]^{T}
$$

For mono-symmetric I-beam there are six design variables, including web height and thickness $\left(h_{w}\right.$ and $\left.t_{w}\right)$, compressed flange width and thickness $\left(b_{f 1}\right.$ and $\left.t_{f 1}\right)$ and tension flange width and thickness $\left(b_{f 2}\right.$ and $\left.t_{f 2}\right)$ :

$$
\mathbf{x}=\left[h_{w}, t_{w}, b_{f 1}, t_{f 1}, b_{f 2}, t_{f 2}\right]^{T}
$$
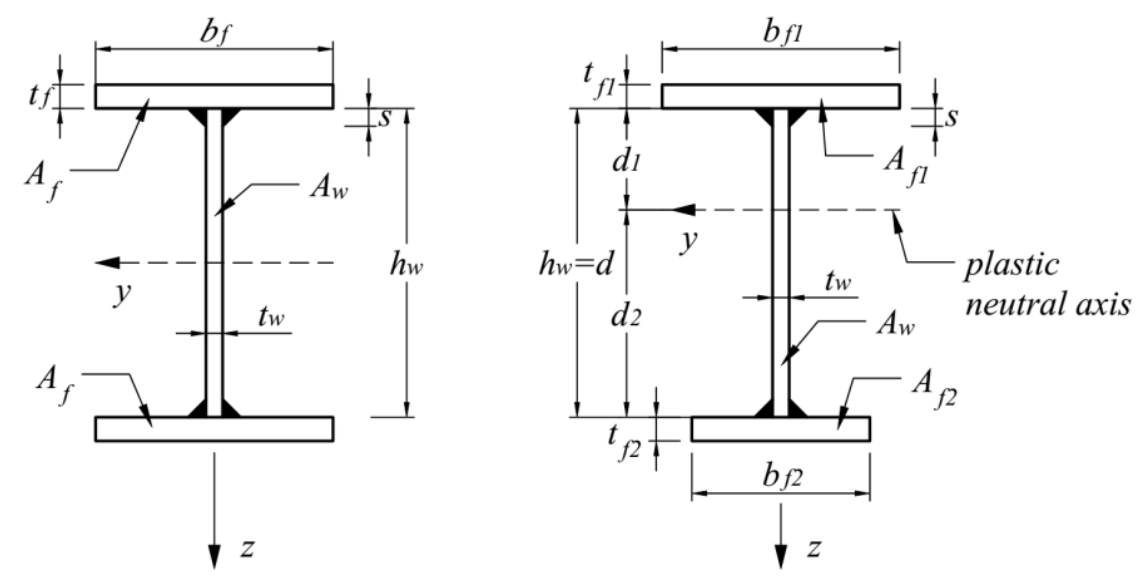

Fig. 2. Doubly symmetric and monosymmetric I-section

In this study, discrete values are used for the web and flanges dimensions. The set of possible values of the plate thicknesses $t_{w}, t_{f}, t_{f 1}$ and $t_{f 2}$ is denoted by $T$ and is defined based on the manufacturer's available dimensions in (mm) as: $T=[6,8,10,12,14,16,18,20,22,24]$. The web height $h_{w}$ is defined with respect to the beam length $L$ by set $H$ which contains integer values from $L / 30$ to $L / 10$ in $10 \mathrm{~mm}$ intervals: $H=[L / 30, \ldots, L / 10]$. Similarly, set $B$ contains the possible flange widths: $B=\left[h_{w} / 4, \ldots, h_{w} / 2\right]$, also in $10 \mathrm{~mm}$ intervals.

\subsection{Objective function}

The objective of the optimization process is to minimize the mass of the prismatic I-beam, so that the cross-sectional area is taken as the objective function. For doubly-symmetric I-beam:

$$
\text { minimize } f(\mathbf{x})=A=A_{w}+2 A_{f}=h_{w} t_{w}+2 b_{f} t_{f}
$$

For monosymmetric I-beam:

$$
\operatorname{minimize} f(\mathbf{x})=A=A_{w}+A_{f 1}+A_{f 2}=h_{w} t_{w}+b_{f 1} t_{f 1}+b_{f 2} t_{f 2}
$$

\subsection{Constraints}

The optimization constraints are formulated according to the steel design code EC 3 [14], [15]. They consider the cross-sectional behaviour and ensure that the solution has sufficient bending resistance about the major axis, shear force resistance and lateral torsional buckling resistance. Due to space limit, only the expressions used as optimization constraints are listed in the paper, but not the expressions for calculating the geometrical characteristics of the crosssections used in them. They can be found in the relevant literature [8], [14], [15].

\subsubsection{Cross-section classification}

The resistance of cross-sections depends on their class. In EC 3, cross-sections are placed into one of four behavioural classes depending upon the material yield strength $f_{y}$, the width-to-thickness ratios of webs and flanges, and the loading arrangement. The optimization algorithm developed in this work includes constraints by which the dimensions of the cross section are determined so that both compressed flange and web belong to class 1 (Fig. 2, Tab. 1). Class 1 crosssections are fully effective under pure compression, and are capable of reaching and maintaining their full plastic moment in bending. 


\begin{tabular}{|l|c|c|}
\hline & Doubly-symmetric I-profile & Mono-symmetric I-profile \\
\hline $\begin{array}{l}\text { Compressed } \\
\text { flange }\end{array}$ & $\left(b_{f}-t_{w}-2 s\right) /\left(2 t_{f}\right) \leq 9 \varepsilon$ & $\left(b_{f 1}-t_{w}-2 s\right) /\left(2 t_{f 1}\right) \leq 9 \varepsilon$ \\
\hline Web & $\left(h_{w}-2 s\right) / t_{w} \leq 72 \varepsilon$ & $\left(h_{w}-2 s\right) / t_{w} \leq \lambda_{K 1}$ \\
\hline & $\varepsilon=\sqrt{235 / f_{y}}$ & $\lambda_{K 1}=\frac{396 \varepsilon}{13 \alpha-1} \quad$ if $\quad \alpha=\frac{d_{1}}{d}>0.5 ; \lambda_{K 1}=\frac{36 \varepsilon}{\alpha} \quad$ if $\quad \alpha=\frac{d_{1}}{d} \leq 0.5$ \\
where: & & $d=h_{w}, d_{1}=\frac{d}{2}-\frac{A_{f 1}-A_{f 2}}{2 t_{w}}$ \\
\hline
\end{tabular}

Table 1. Cross-section classification

\subsubsection{Bending resistance}

The bending resistance about the major axis is defined as:

$$
M_{E d} / M_{c, R d} \leq 1
$$

where $M_{E d}$ is the design bending moment and $M_{c, R d}$ is the bending resistance about the major $y$ axis of the cross-section. For Class 1 cross-sections the plastic bending resistance is employed:

$$
M_{c, R d}=\frac{W_{p l, y} f_{y}}{\gamma_{M 0}}
$$

where $W_{p l}$ is the plastic section modulus and $\gamma_{M 0}$ is the partial safety factor $\left(\gamma_{M 0}=1\right)$. In a monosymmetric section with fully plastic stress distribution bent in a plane of symmetry the plastic neutral axis divides the cross-section into two equal areas so that there is no axial force resultant, but unlike doubly-symmetric section the neutral axis no longer passes through the centroid of the cross-section.

\subsubsection{Shear resistance}

The shear resistance constraint is:

$$
V_{E d} / V_{p l, R d} \leq 1
$$

where $V_{E d}$ is the design shear force, and $V_{p l, R d}$ is the plastic shear resistance:

$$
V_{p l, R d}=\frac{A_{v}\left(f_{y} / \sqrt{3}\right)}{\gamma_{M 0}}
$$

The shear area $A_{v}$ is the area of the cross-section that can resist the applied shear force with a moderate allowance for plastic redistribution. For welded I-sections, with load parallel to the web, this is the area of the web:

$$
A_{v}=\eta h_{w} t_{w}
$$

where the value of coefficient $\eta$ depends on steel grades. The resistance of the web to shear buckling need not be considered provided:

$$
\frac{h_{w}}{t_{w}} \leq 72 \frac{\varepsilon}{\eta}
$$

\subsubsection{Lateral torsional buckling}

The load at which this buckling occurs may be substantially less than the beam's in-plane load resistance. For an idealized perfectly straight elastic beam, there are no out-of-plane deformations until the applied moment $M_{E d}$ reaches the elastic buckling moment $M_{c r}$, when the beam buckles by deflecting laterally and twisting. 
Real beams differ from the ideal beams due to the possible impact of many imperfections, such as initial deformation, eccentricity of load, residual stresses or variations in material properties. For the EC3 method of designing against lateral torsional buckling, the design bending moment $M_{E d}$ must be less than the lateral torsional buckling resistance $M_{b, R d}$ and checks should be carried out on all unrestrained segments of beams:

$$
M_{E d} / M_{b, R d} \leq 1
$$

The lateral torsional buckling resistance for Class 1 cross-sections is defined as:

$$
M_{b, R d}=\chi_{L T} W_{p l, y} \frac{f_{y}}{\gamma_{M 1}}
$$

where $\chi_{L T}$ is a reduction factor and $\gamma_{M I}$ is the safety factor $\left(\gamma_{M I}=1\right)$. The reduction factor for lateral torsional buckling is described through equation:

$$
\chi_{L T}=\frac{1}{\phi_{L T}+\sqrt{\phi_{L T}^{2}-\bar{\lambda}_{L T}^{2}}} \text { but: } \chi_{L T} \leq 1.0
$$

where:

$$
\phi_{L T}=\left[1+\alpha_{L T}\left(\bar{\lambda}_{L T}-0.2\right)+\bar{\lambda}_{L T}^{2}\right]
$$

In (16), $\alpha_{L T}$ is the imperfection factor corresponding to the appropriate buckling curve. Relative slenderness for lateraltorsional buckling is defined as:

$$
\bar{\lambda}_{L T}=\sqrt{\frac{W_{p l, y} f_{y}}{M_{c r}}}
$$

where $M_{c r}$ is the elastic critical moment for lateral torsional buckling based on gross cross-sectional properties and taking into account the load conditions, the real moment distribution and the lateral restraints. It can be estimated using expression (18), proposed by Clark, Hill and Galéa [15].

$$
M_{c r}=C_{1} \frac{\pi^{2} E I_{z}}{\left(k_{z} L\right)^{2}}\left[\sqrt{\left(\frac{k_{z}}{k_{w}}\right)^{2} \frac{I_{w}}{I_{z}}+\frac{\left(k_{z} L\right)^{2} G I_{t}}{\pi^{2} E I_{z}}+\left(C_{2} z_{g}-C_{3} z_{j}\right)^{2}}-\left(C_{2} z_{g}-C_{3} z_{j}\right)\right]
$$

where:

- $\mathrm{C} 1, \mathrm{C} 2$ and $\mathrm{C} 3$ are coefficients depending on the shape of the bending moment diagram, the support conditions and the distance between the centre of gravity and the shear centre;

- $\mathrm{kz}$ and kw are effective length factors that depend on the support conditions at the end sections. Factor kz is related to rotations at the end sections about the weak axis $\mathrm{z}$, and $\mathrm{kw}$ refers to warping restriction in the same cross sections. These factors vary between 0.5 (restrained deformations) and 1.0 (free deformations), and are equal to 0.7 in the case of free deformations at one end and restrained at the other;

- $\mathrm{zg}$ is the distance between the centre of shear and the point at which the transverse load acts, which can be determined as $z g=z Q-z s$, where $z Q$ and $z s$ are the coordinates of the point of application of the load and of the shear centre, relative to the centroid of the cross section. These quantities are positive if located in the compressed part and negative if located in the tension part.

- $\quad \mathrm{z}$ is a parameter that reflects the degree of asymmetry of the cross section in relation to the $\mathrm{y}$ axis. It is zero for doublysymmetric cross section and takes positive values when the flange with larger second moment of area about $\mathrm{z}$ is the compressed flange.

- IT is the torsion constant, Iw is the warping constant, Iz is the second moment of area about the minor axis and L is the length of the beam between points of lateral restraint.

\section{Numerical examples}

There are three types of parameters that should be given as input data to the developed algorithm as follows: 
1. Material properties of the beam, i.e. material yield strength $\left(f_{y}\right)$, Young's modulus of elasticity $(E)$ and Poisson's ratio $(v)$.

2. Geometric properties of the beam, including beam length $(L)$ and effective length factors that depend on the rotation and warping restraints at the end cross sections $\left(k_{z}\right.$ and $\left.k_{w}\right)$.

3. Loading conditions, i.e. permanent and variable distributed loads applied to the beam $\left(q_{G}\right.$ and $\left.q_{Q}\right)$, partial factors of safety for permanent and variable actions $\left(\gamma_{G}\right.$ and $\left.\gamma_{Q}\right)$, coefficients depending on the loading conditions $\left(C_{l}\right.$, $C_{2}$ and $C_{3}$ ) and load position.

In the represented examples, the following values are used:

1. $f_{y}=235 \mathrm{MPa}, E=210000 \mathrm{MPa}, v=0.3$

2. $k_{z}=k_{w}=1$, five spans were considered: $L=8,10,12,14$ and $16 \mathrm{~m}$

3. Distributed loads: $q_{G}=3 \mathrm{kN} / \mathrm{m}, q_{Q}=5 \mathrm{kN} / \mathrm{m}$

$\gamma_{G}=1.35, \gamma_{Q}=1.5, C_{l}=1.132, C_{2}=0.459, C_{3}=0.525$

The distributed loads are acting on the top flange.

The load cases with the corresponding beam lengths are given in Tab. 2. Design distributed load $q_{d}$, shear force $V_{E d}$ and bending moment $M_{E d}$ are calculated using (19):

$$
q_{d}=\gamma_{G} q_{G}+\gamma_{Q} q_{Q}, \quad V_{E d}=q_{d} L / 2, M_{E d}=q_{d} L^{2} / 8
$$

\begin{tabular}{|c|c|c|c|c|}
\hline $\begin{array}{c}\text { Load } \\
\text { case }\end{array}$ & $\begin{array}{c}\mathrm{L} \\
(\mathrm{m})\end{array}$ & $\begin{array}{c}q_{d} \\
(\mathrm{kN} / \mathrm{m})\end{array}$ & $\begin{array}{c}V_{E d} \\
(\mathrm{kN})\end{array}$ & $\begin{array}{c}M_{E d} \\
(\mathrm{kNm})\end{array}$ \\
\hline $\mathrm{L} 8$ & 8 & 11.55 & 46.20 & 92.40 \\
\hline $\mathrm{L} 10$ & 10 & 11.55 & 57.75 & 144.38 \\
\hline $\mathrm{L} 12$ & 12 & 11.55 & 69.30 & 207.90 \\
\hline $\mathrm{L} 14$ & 14 & 11.55 & 80.85 & 282.98 \\
\hline $\mathrm{L} 16$ & 16 & 11.55 & 92.40 & 369.60 \\
\hline
\end{tabular}

Table 2. Load cases

The results of the optimization processes for doubly symmetric and for monosymmetric I-beams are presented in Tab. 3 and Tab. 4, respectively. Since genetic algorithm uses random processes, an algorithm run at different times from the same starting point can generate different design histories and local minima. Therefore, a particular problem needs to be run several times before the solution is accepted as the global optimum [10]. The results in these tables represent the best obtained results after five consecutive runs for every loading case.

\begin{tabular}{|c|c|c|c|c|c|}
\hline & L8 & L10 & L12 & L14 & L16 \\
\hline$b_{f} \times t_{f}(\mathrm{~mm})$ & $170 \times 16$ & $210 \times 18$ & $210 \times 24$ & $260 \times 24$ & $310 \times 24$ \\
\hline$t_{w} \times h_{w}(\mathrm{~mm})$ & $6 \times 350$ & $6 \times 420$ & $8 \times 430$ & $8 \times 520$ & $10 \times 620$ \\
\hline$A\left(\mathrm{~mm}^{2}\right)$ & 7540 & 10080 & 13520 & 16640 & 21080 \\
\hline$A_{w} / A$ & 0.28 & 0.25 & 0.25 & 0.25 & 0.29 \\
\hline $2 A_{f} / A$ & 0.72 & 0.75 & 0.75 & 0.75 & 0.71 \\
\hline
\end{tabular}

Table 3. Optimization results for doubly-symmetric I-beams

\begin{tabular}{|c|c|c|c|c|c|}
\hline & $\mathrm{L} 8$ & $\mathrm{~L} 10$ & $\mathrm{~L} 12$ & $\mathrm{~L} 14$ & $\mathrm{~L} 16$ \\
\hline$b_{f 1} \times t_{f 1}(\mathrm{~mm})$ & $220 \times 14$ & $270 \times 16$ & $310 \times 18$ & $360 \times 20$ & $400 \times 22$ \\
\hline$t_{w} \times h_{w}(\mathrm{~mm})$ & $6 \times 450$ & $6 \times 560$ & $6 \times 690$ & $8 \times 720$ & $8 \times 810$ \\
\hline$b_{f 2} \times t_{f 2}(\mathrm{~mm})$ & $120 \times 10$ & $150 \times 10$ & $180 \times 10$ & $180 \times 12$ & $210 \times 12$ \\
\hline$A\left(\mathrm{~mm}^{2}\right)$ & 6980 & 9180 & 11520 & 15120 & 17800 \\
\hline$A_{w} / A$ & 0.39 & 0.37 & 0.36 & 0.38 & 0.36 \\
\hline$\left(A_{f 1}+A_{f 2}\right) / A$ & 0.61 & 0.63 & 0.64 & 0.62 & 0.64 \\
\hline$A_{f 1} / A_{f 2}$ & 2.57 & 2.88 & 3.10 & 3.33 & 3.49 \\
\hline$\beta$ & 0.90 & 0.90 & 0.90 & 0.93 & 0.93 \\
\hline
\end{tabular}

Table 4. Optimization results for monosymmetric I-beams

In addition to the web and flanges dimensions, these tables give the ratios of the web area and the flanges area in the total cross-sectional area. In Tab. 4 , there is also given the measure of monosymmetry of the cross-section $\beta$, which is defined as $\beta=I_{f c}\left(I_{f c}+I_{f t}\right)$, where $I_{f c}$ and $I_{f t}$ are the section minor axis second moments of area of the compression and tension flanges, respectively. 
The ratios of optimized cross-sectional areas for doubly symmetrical and monosymmetrical I-beams are given in Tab. 5. For better comparison of these values, the total optimized cross-sectional areas for both I-beam types are also graphically represented in Fig. 3.

\begin{tabular}{|c|c|c|c|c|c|}
\hline & L8 & L10 & L12 & L14 & L16 \\
\hline$A_{\text {doubly }}\left(\mathrm{mm}^{2}\right)$ & 7540 & 10080 & 13520 & 16640 & 21080 \\
\hline$A_{\text {mono }}\left(\mathrm{mm}^{2}\right)$ & 6980 & 9180 & 11520 & 15120 & 17800 \\
\hline$A_{\text {doubl } 1} / A_{\text {mono }}$ & 1.08 & 1.10 & 1.17 & 1.10 & 1.18 \\
\hline
\end{tabular}

Table 5. Comparison of optimized cross-sectional areas for doubly symmetric and monosymmetric I-beams

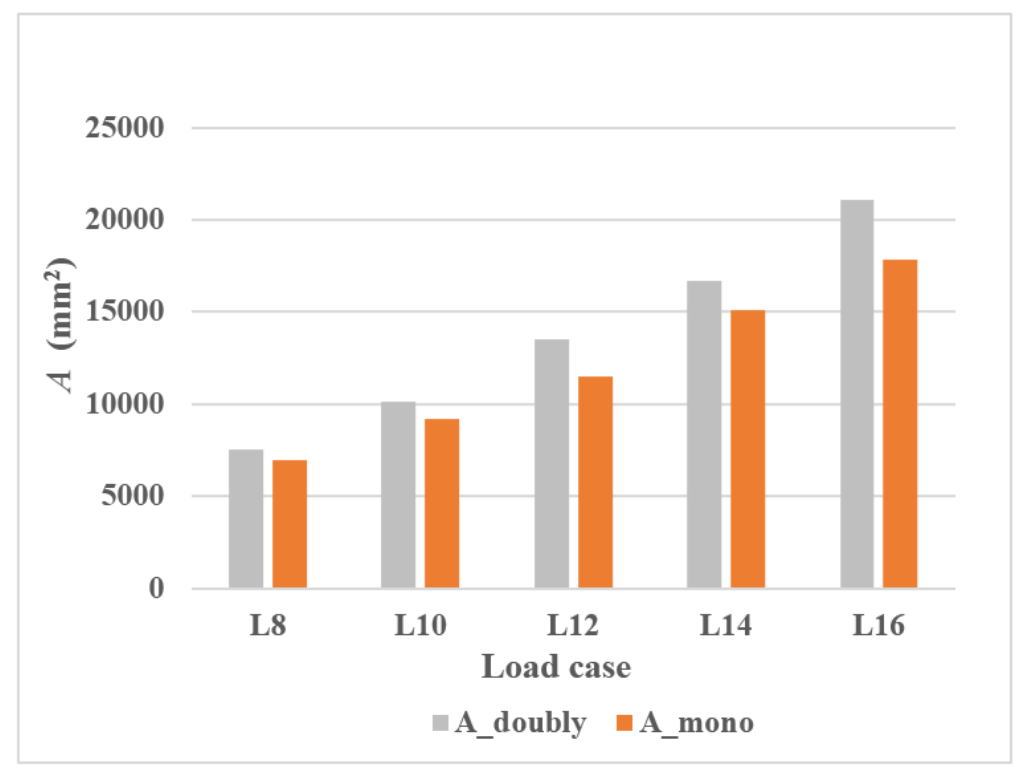

Fig. 3. Comparison of optimized cross-sectional areas

The results of the optimization process indicate that according to EC3 design rules substantial savings in weight can be achieved for I-beams under uniform transverse load by employing monosymmetrical cross-sections. In the examples of the present study, it has been shown that the weight reduction can be up to $18 \%$ (Tab. 5). However, the results show that optimized monosymmetric beams are significantly higher than doubly symmetric beams, which may be a limiting factor for their application in certain types of structures.

The results have also confirmed that the optimization process of monosymmetric I-beams leads to a conventional design with wide compression and narrow tension flange, which can also be seen in the fig. 4, showing a comparison of the optimized shapes for the load case L10. For the presented load cases, the cross-sectional area ratios of the compressed to tension flange can range from approximately 2.5 to 3.5 (Tab. 4). The measure of monosymmetry of the cross-section $\beta$ ranges from 0.90 to 0.93 . The average percentages of the web and the flanges area in the total cross-section area are $26 \%$ and $74 \%$ for doubly symmetric I-beams, i.e. $37 \%$ and $63 \%$ for monosymmetric I-beams.

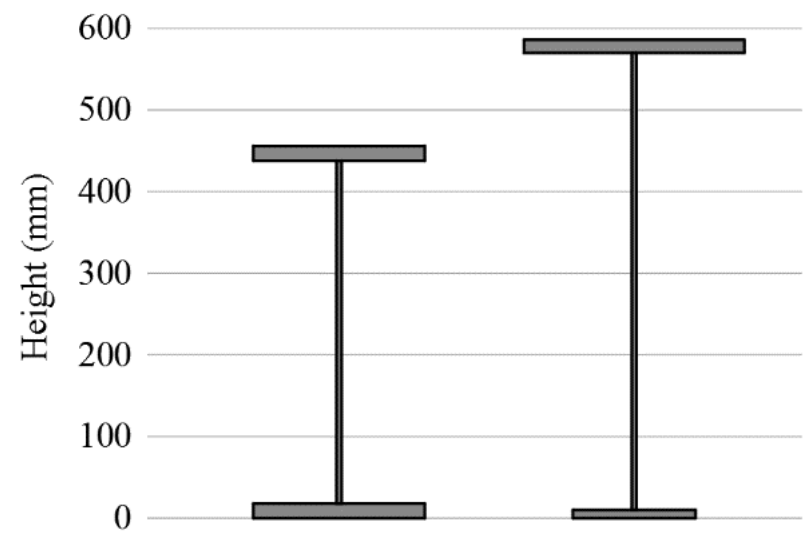

Fig. 4. Comparison of optimized I-beams for load case L10 


\section{Conclusion}

It is important to notice that design according to EC3 is often an iterative process. Initial assumptions about crosssectional dimensions are made and after calculations it might be necessary to revise them and start from the beginning. A large number of design possibilities that meet the design rules create thereby the problem of choosing the most economical design. It is very difficult to find the optimal solution by trial and error, therefore the automated search by optimization techniques should be used, whenever possible.

In this paper, a program code for optimization of a doubly symmetric and monosymmetric built-up I-beam welded sections in Class 1 for a laterally unrestrained beam subjected to bending around its major axis has been developed. It has been confirmed that optimized forms of monosymmetric I-beams possess higher bearing capacity to lateral torsional buckling than the doubly symmetric I-beams. The optimization problem is defined with discrete variable values. Plate thicknesses are based on the manufacturer's available dimensions. Web height and flanges widths are also defined as discrete integer values in $10 \mathrm{~mm}$ increments, but the program code also allows the input of some other arbitrarily selected incremental value and the automatic adjustment of the lower and upper limits for the dimensions to be optimized.

In the present study the objective function is the weight of the beam. Beside the minimum weight design the most economical solution should also consider a manufacturing cost function of these sections, which is intended to be taken into account in further work. Also, the optimization algorithm should be extended to include not only the plastic analysis with I-sections in Class 1, but to allow analysis for an arbitrarily selected cross-section class.

\section{References}

[1] Jarmai, K.; Snyman, J.A; Farkas, J. \& Gondos, G. (2003). Optimal design of a welded I-section frame using four conceptually different aptimization Available from: https://www.researchgate.net/publication/226325896_Optimal_design_of_a_welded_Isection_frame_using_four_conceptually_different_optimization_algorithms, Accessed: 2020-05-15

[2] Gil-Martin, L.M.; Aschheim, M. \& Hernández-Montes, E. (2008). Proportioning of steel beam-column members based on RSD optimization methodology, Engineering Structures 30, 3003-3013, doi:10.1016/j.engstruct.2008.04.004

[3] Carbonell-Marquez, J. F.; Gil-Martin, L.M. \& Hernández-Montes, E. (2013). Strength design optimization of structural steel members according to Eurocode 3, Journal of Constructional Steel Research 80, 213-223, http://dx.doi.org/10.1016/j.jcsr.2012.07.019

[4] Ozbasaran, H. (2018). Optimal design of I-section beam-columns with stress, non-linear deflection and stability constraints, Engineering Structures 171, 385-394, https://doi.org/10.1016/j.engstruct.2018.05.110

[5] Salmon, C.G. (2009). Steel Structures - Design and Behaviour, Pearson Prentice Hall, ISBN-13: 978-0131885561

[6] Mela, K. \& Heinisuo, M. (2014). Weight and cost optimization of welded high strength steel beams, Engineering Structures 79, 354-364, http://dx.doi.org/10.1016/j.engstruct.2014.08.028

[7] Ozbasaran, H. \& Yilmaz, T. (2018). Shape optimization of tapered I-beams with lateral-torsional buckling, deflection and stress constraints, Journal of Constructional Steel Research 143, 119-130, http://dx.doi.org/10.1016/j.jcsr.2017.12.022

[8] Trahair, N.S.; Bradford M.A.; Nethercot, D.A. \& Gardner, L. (2008). The Behaviour and Design of Steel Structures to EC3, Taylor \& Francis, ISBN-13: 978-0415418669

[9] Rao. S.S. (2009). Engineering Optimization Theory and Practice, John Wiley \& Sons, ISBN 978-0-470-18352-6

[10] Arora, J.S. (2017). Introduction to Optimum Design, Elsevier, ISBN: 978-0-12-800806-5

[11] Hrubina, K.; Katalinic, B.; Jadlovska, A.; Wessely, E.; Macurova, A. \& Majercak, J. (2010). Modeling and Computing Methods for Solving Optimization Problems, Chapter 42 in DAAAM International Scientific Book 2010, pp. 471-488, B. Katalinic (Ed.), Published by DAAAM International, ISBN 978-3-901509-74-2, ISSN 17269687, Vienna, Austria, DOI: 10.2507/daaam.scibook.2010.42

[12] Kramer, O. (2017). Genetic Algorithm Essentials, Springer International Publishing, ISBN 978-3-319-52155-8

[13] Maskaoui, Z., Jalal, S. \& Bousshine L. (2017). Genetic Algorithm Parameters Effect on the Optimal Structural Design Search, IOSR Journal of Mechanical and Civil Engineering (IOSR-JMCE) e-ISSN: 2278-1684,p-ISSN: 2320-334X, Volume 14, Issue 3 Ver. V., pp 124-130

[14] CEN, Eurocode 3: Design of Steel Structures. Part 1-1: General Rules and Rules for Buildings, European Comittee for Standardization, Brussels, 2005

[15] Da Silva, L.S.; Simoes, R. \& Gervasio, H. (2010). Design of Steel Strucures, Eurocode 3: Design of steel structures Part 1-1 - General rules and rules for buildings, Ernst \& Son, ISBN: 978-3-433-02973-2 